\title{
Effectiveness of psychometric tests for the selection of personnel in jobs in the retail sector
}

\section{Cristian Chipana-Castillo ${ }^{a}$, Gabriela-Jhennyfer Miranda-Roca ${ }^{a}$ and Wagner Vicente-Ramos ${ }^{a^{*}}$}

\begin{tabular}{l}
${ }^{a}$ Universidad Continental, Peru \\
\hline C H R O N I C L E \\
\hline Article history: \\
Received: September 18, 2020 \\
Received in revised format: \\
November 182020 \\
Accepted: December 12, 2020 \\
Available online: \\
December 15, 2020 \\
\hline Keywords: \\
Psychometric tests \\
Personnel selection \\
Interviews \\
IQ tests and personality tests
\end{tabular}

\section{Introduction}

All companies today have challenges in finding the most suitable personnel for various positions within an organization. Due to the current reality, the demand for labor has caused multiple candidates to be found to meet the requirements for the required position. According to Chiavenato (2007) the selection of personnel is part of the integration of human resources and this is the step after recruitment. Recruitment and selection of personnel should be considered as two phases in the same process: the first phase, the entry of candidates into the organization, which is based on outreach activities, attracting attention, increasing the entry of candidates, that is, an activity of inviting potential candidates. The second phase, which is the selection, involves activities of; choosing, deciding, selecting, classifying, filtering and restricting, which is the phase where all the selection techniques are applied for. Castaño, López and Prieto (2011) in the human resources processed a series of methods and techniques of evaluation. They used different types of evaluation tests; specific knowledge tests, psychometric tests, interviews, work samples, situational tests, group dynamics, among others. Regardless of the nature of the selection technique used, these must meet requirements; the assessment methods must be adequate according to the criteria of the position and meet the requirements of reliability and validity in writing, as for psychological tests these must act ethically and professionally ensuring that the person using them has the necessary and sufficient skills for their use.

According to Wayne (2010) many companies have added specific tests to their hiring processes. These tests evaluate factors such as aptitude, personality, skills and motivation of potential employees and allow managers to better choose the candidate as this method can predict the individual's performance in a job. Over the years, it has been determined that personnel selection is basically a process of comparison between two variables: on the one hand, the requirements of the vacant position and on the other hand, the profile of the characteristics of the candidates presented. The first variable is provided by the description

* Corresponding author.

E-mail address: wvicente@continental.edu.pe (W. Vicente-Ramos) 
and analysis of positions, while the second is obtained through the application of selection techniques, Pascale, Asselin and Paré (2013) consider that a psychometric test for personnel selection involves a series of standardized questions or stimuli which are administered under predefined conditions in which individuals exhibit personality related to the skills sought for the job. It appears necessary to choose the right tests for the selection favors of the potential for discrimination at the time of selection, and at the same time, updating the selection tests in order to establish standardized processes in the selection of personnel and to guarantee a fair process for all candidates. All results obtained should be used only for employment purposes, always explaining to the candidate the what and why of each test, and of which only the personnel in charge should handle such selection processes. Psychological research has been concerned with human behavior for many years, giving way to social desirability that can be considered positively, as an expression of social competence, that is, a person who shows behavior has the ability to discern what kind of behavior is expected in a particular social context, and is able to adapt quickly and process all relevant information adequately. Seeing it from the other extreme, social desirability can be perceived simply as a representation of a false image of reality, where the individual shows a desired behavior since this can result in obtaining certain advantages for the individual such as being selected in a recruitment and selection of a person. In recruitment there are several reasons why social desirability is a problem since, in methods such as interviews or self-description questionnaires, it is relatively simple for applicants to present themselves in a positive light since all they have to do is determine what type of behavior is socially desirable in the specific situation and give the respective answers according to Kanning and Kuhne (2006).

When Latin America joins the system of world capitalism, a dominant political thought is generated in the industrial societies, then Peru becomes an attractive market for private investments so the processes of recruitment and selection of personnel are applied only by companies of the private sector being these a minority, In most Latin American countries, informal jobs are predominant and in the public sector, promotions or hiring occur only through public competitions in which the selected candidate only meets the requirements for the position, leaving aside the use of selection or promotion instruments that could help choose the most suitable candidate for the required position Jiménez and Iguiñiz (2010). The National Institute of Statistics and Information Technology of Peru - National Survey of Households by Geographical Domain in 2019 shows that of the total of thirteen million 360 thousand 200 people who are employed in urban areas, $33.6 \%$ are equivalent to about four million 488 thousand six hundred people who would have a formal job, which would explain that only that percentage have a labor bond subject to the rules of the state, and the Ministry of Labor and thus belong to the formal sector of the Peruvian economy. Geographical domains mention that in Peru formal employment decreased on the Coast by 1.3\% (42,500); thus it fell on the Central Coast by $1.5 \%(38,500)$, on the North Coast by $1.4 \%(9,000)$; while it grew on the South Coast by $5.3 \%(5,000)$. In the Sierra it increased by $4.1 \%$, mainly in the Central Sierra by $10.0 \%$, in the Southern Sierra by $1.4 \%$ and in the Northern Sierra by $0.6 \%$. In La Selva it increased by $13.4 \%$. It is a clear observation that companies have seen a more optimal market to get involved in the interior of the country and even the data already seen regarding the sierra is more promising. Considering that Huancayo is an attractive market for the retail sector, companies like; Tottus, Saga Falabella, Metro, Plaza Vea, Ripley among others, have come to have a favorable acceptance.

In Peru, the unemployment rate has increased by 8 percent, according to the Peruvian newspaper Gestión Peruano in the months of March to July 2020 due to the COVID 19 and we can realize the importance of proper management of human resources in companies for recruitment and selection of personnel, since through the factors already seen, the person will seek in many ways to be desirable in the eyes of the recruiter then, according to Ferro and Vives (2004) we need to ask what is meant by effectiveness, efficiency and efficiency and above all, how these studies are made and who performs them. To do this we must begin with the term of effectiveness, which has to do with the degree of satisfaction of the recruiter against the candidate, the effectiveness points to social success and satisfaction of those who apply it. This leads us to a problem that leads directly to effectiveness, that is, to the question: Is the battery of tests really useful? Let's think about the number of people who go to a doctor. As hard as it may seem, therapy in this sense becomes effective, the same applies to the selection process of personnel. What the recruiter is interested in is the effectiveness of the application of his or her resources. Although effectiveness is "a good outcome", the recruiter should not rely on it being the "good outcome" and should focus on the variables that each process seeks to achieve.

\section{Literary review}

\subsection{Selection of personnel}

Calderón, Acosta and Gallego (2017) define that the selection of personnel is: "To choose the most suitable and appropriate candidate, who possesses attitudes and capacities that help to strengthen and grow the company and so can occupy the position effectively, fulfilling the requirements demanded by the company and generating the expected performance". Also, according to (Chiavenato, 2011), the selection of personnel is defined as "It consists of choosing the right man for the right place, the selection looks for the most suitable for the available position to increase the effectiveness of the organization".

\subsection{Choice of personnel selection techniques}

Having the information regarding the vacant positions, the next step of the right selection techniques is to choose the right candidates. The selection techniques can be classified into five groups (Chiavenato, 2007). 
2.2.1. Selection interview: In this group there are three groups, the first one that directs this group has a certain orientation, the second group is considered as non-directed or free and mixed.

2.2.2. Direct or Directed Interview: This is a concrete interview that has pre-set questions such as: What is your academic background? or How many years of work experience do you have; with these questions the candidate is expected to give concrete answers.

2.2.3. Free interview: This type of interview has few questions, but these are open-ended, for example: What can you bring to the organization? or Tell me about yourself. It is expected that the candidate gives structured and clear answers where communicative fluency becomes essential and observe the behaviors that the candidate possesses.

2.2.4. Mixed interview: These interviews are more frequent in organizations, here are prepared open and closed questions that the candidate has to answer.

\subsection{Tests of knowledge or skills}

They are tools to evaluate objectively the knowledge and skills that are acquired through the course of time by study and practice, in the instruments of knowledge are general questions of languages and finally the specific ones there are covered on the professional culture of technical knowledge.

2.3.1. WAIS Test: The intelligence scale is applied to adults to allow obtaining the IQ (Amador, 2013), it mentions that the test is made up of fifteen tests (ten main ones and five optional ones), which are grouped into four indexes:

- Verbal comprehension

- Perceptual reasoning

- Work memory

- Processing speed

The total intelligence quotient is obtained from the result of the ten main tests. In addition to the above, the author indicates that this test allows an index of general ability to be obtained through the scores of the three tests of verbal comprehension and perceptual reasoning.

2.3.2. Raven's progressive matrix test: The purpose is to measure the IQ. This tool is divided into five series (A, B, C, D, E) each series consists of 12 items, it is a non-verbal test where the subject must describe the missing pieces in a series of sheets for this, the perceptual skills of both observation and reasoning are used to deduce missing pieces according to (González, 2007).

2.3.3. Terman Merrill Test: Its objective is to measure IQ in terms of comprehension, concentration, analytical ability, planning, numerical and verbal ability and decision-making. This test consists of 10 subtopics that evaluate intelligence through 6 areas: general intelligence, fluid reasoning, quantitative reasoning, knowledge, visual-spatial process and working memory. This test allows us to understand the person's intellectual capacity by going deeper into specific aspects, as well as a complete description of the general intellectual level. It provides specific information regarding the person's mental age and chronological age.

2.3.4. Moss test: It is used mainly in the recruitment process for the proper selection of suitable personnel, especially when it comes to senior management positions, management positions and supervisory positions, because they are subjected to situations in which they must demonstrate their ability to make decisions, the level of leadership to efficiently perform their duties in the organization, the ability to assess interpersonal problems, ability to establish interpersonal relationships and finally the common sense and tact for interpersonal relationships. This test consists of 30 questions or situations where the candidates have a period of 15 to 20 minutes to answer 8 questions, each question has 4 possible answers the candidate must choose an answer for the situation or question raised, in this test does not pass or fail only the candidate will be chosen that presents better leadership skills, decision making and the ability to establish good interpersonal relationships.

\subsection{Personality tests}

Personality is the set of traits and qualities that make up a person's way of being, makes him/her different from others. Since personality characterizes human beings, it is a determining factor within the work environment, because every human being has his or her own way of thinking and reacting to any stimulus. This type of psychometric evaluation is mainly oriented to know whether or not a person can adapt to a new environment, whether or not they can adapt to change or they have good interpersonal relationships and are capable of performing a given task efficiently, under stress and mainly if they can look for solutions without being startled or mentally affected. Candidates must take both expressive and projective exams, and lastly, motivation, frustration and interest inventories (Fong, 2019). 
2.4.1. 16-PF by Raymont Cattell: Its objective is to make an analysis of the traits and response styles of the person to be evaluated, in order to obtain with its interpretation a basic profile of the candidate's personality. This personality test is very useful because it is applied in areas of organizational and human resources psychology. The test measures the structure of the personality in 16 factors: affability, reasoning, stability, dominance, animation, attention to rules, daring, sensitivity, vigilance, abstraction, privacy, apprehension, openness to change, self-sufficiency, perfectionism, tension. The 5 dimensions or global factors of second order are: extraversion, anxiety, hardness, independence and self-control. The test consists of 105 items, in each item the subject must decide between three alternatives for his possible response that best fits his particular case. The answers given by the candidate are analyzed in terms of global dimensions that are used to be extracted from the scores in order to analyze and interpret the score of each of the 16 scales with the help of the test and its external guides.

2.4.2. Eysenck Personality Test: Serves to measure two important dimensions of personality: introversion - extroversion and neurotism (stability - instability). Each form contains 57 elements with yes and no answers, the lie score has 9 points, in this item is measured what the candidate wants to manifest with his answers, but those who score 5 or more it is deduced that the candidate is trying to look good and are not honest with their answers. The "E" score is 24 items, here it is measured if the candidate is outgoing and finally the "N" score that measures how neurotic the candidate is. In this test you can appreciate the personality of the subject and thus determine whether it is in line and suitable for the required job profile

\subsection{Selection techniques:}

These techniques are used in the selection process of personnel in the organizations, there are several organizations that carry out this process by their own means

2.5.1. The interview: Matabajoy, Matabachoy and Obando (2018) mention that the situational assessment interview is a process designed to simulate situations that commonly occur in a working day. Its objective is to measure the knowledge, skills, and personality of the job applicant in a given situation through different exercises. The benefit of these interviews consists of an evaluation in which more real results can be obtained about the candidate. The author indicates that this process consists of three types, which are:

1. Structured: Consists of a situation or incident that contains a series of questions that the candidate must answer in a given time.

2. Developmental: It represents an environment of change through an exercise that contains specific questions that each candidate must recognize and answer.

3. Interactive: In this process each candidate must change thoughts and ideas through role-playing, with which the desired results are achieved.

2.5.2. Group Dynamics: In this technique, the candidate's ability to work in a team, leadership, and verbal communication, among others, are known. This situation is formed by the same group of candidates.

2.5.3. Written tests: Used to determine suitable candidates, in some cases these tests are taken prior to the interview. Within these tests are mentioned psychometric tests (where various aspects of personality are measured), aptitude tests (numerical, verbal and abstract) and knowledge tests (analytical skills, exercises and practical problems).

2.5.4. Assessment center: Also known as evaluation center, is a selection methodology this technique lasts between one or two days and increasingly used by organizations, with this technique you can analyze the skills or abilities that each candidate has because the variety of situations that will represent each one will be reflected in their behavior either in isolation or try to have interaction with other candidates, in those moments will be reflected as would be their performance in the organization.

\subsection{Psychometric tests}

According to Vargas (2016) "They are a structured tool that covers a wide variety of fields of work, some of which are more applicable, such as clinical, organizational and educational psychology, among others". Psychometric tests, also known as psychological tests, are structured instruments, i.e., people have to choose from the alternatives the answer that is possible according to their criteria or that fits better in their particular case. Psychometry is linked to psychological assessment, which deals with the construction and development of measurement instruments, ensuring that the instruments are properly standardized and have the required validity, making it possible to measure and differentiate some people in relation to others in a given population. 
The psychometric tests aim to achieve a wider information of the subject, which will allow to have more knowledge about the subject. The results obtained from the intelligence and aptitude tests can be good predictors of the future performance of the individual in different situations according to (González, 2007).

\subsubsection{Effectiveness of Psychometric Tests}

The effectiveness of psychometric tests in the last decades has evolved and it has been proven that they are effective. That is why the private and public sectors are making use of psychometric tests when selecting personnel, studies are being carried out to see which tests are more effective in the selection of personnel, they require that they be of minimum cost and that maximum results are obtained when selecting the ideal personnel for the required job. The effectiveness of the tests provides a degree of satisfaction in the company since it will recruit the staff with greater ability and their skills are consistent with the functions required to perform the functions required in the position to meet the objectives. These tests have an effectiveness since it produces changes at the time of recruiting personnel, because they help measure the skills that each candidate has mentioned (Ferro \& Vives, 2004).

\subsubsection{Interpretation of psychometric test scores}

Tovar (2007) mentions that the numbers obtained from psychometric tests are called direct scores or grades. These scores do not have a precise meaning and acquire a psychometric meaning when compared to a table or scale, which has been constructed with the scores obtained in the test. When comparing, we can group or classify the tested subjects with which the purpose of the test would be achieved, so that the right person can be selected to occupy the job. Likewise, the direct scores are transformed into various types of scores that are presented in the scales. The scale is a table that regulates the norms, which transform direct scores into derived scores that are statistically interpretable. These scores are classified as follows:

a) Percentiles: These are scores derived from the psychometric test that transforms the direct score into a scale from 1 to 100 , with each point being called a centile.

b) Standard Score: Are those obtained as a unit at fractions of the standard deviation. For example, the IQ score, the score has a scale from 1 to 9 , the decay score has a scale from 1 to 10 , it is also a score derived from mental age.

\section{Research model and hypothesis}

For the independent variable, Digital Transformation, the following conceptual constructs and their respective items were considered:

a) Interview: Digital customer service technologies provide a personalized experience (EAC1), digital channels offer a rapid response in customer service (EAC2), customer satisfaction is measured on an ongoing basis (EAC3) and digital processes protect customer data privacy (EAC4)

b) Knowledge test: The training provided by the company on digital tools is adequate (CC1), I adapt myself adequately to the digitalization process required by the company (CC2) and I feel committed to the work I carry out in the company's digitalization process (CC3).

c) Personality test: The digitization of processes of the high management contributes to the good functioning of the whole organization (P1), the digitization of processes of your team supervisors contributes to the achievement of your objectives (P2) and the digitization of processes in your office has improved the efficiency in customer service (P3).

For the variable Effective Personnel Selection (ESP), the following items were considered: E1 and E3

From which the following conceptual model and hypothesis are established.

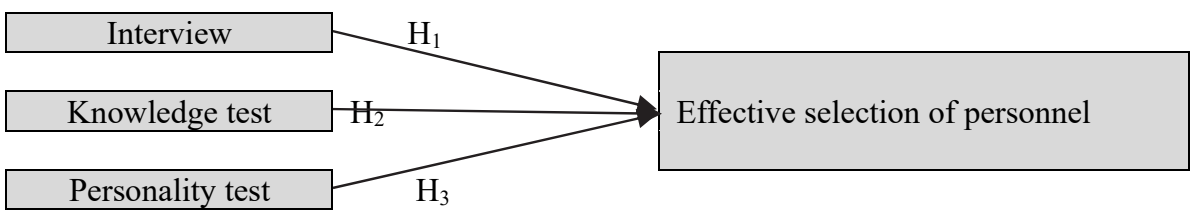

Fig. 1. Conceptual model and hypothesis

$\mathrm{H}_{1}$ : The interview has a positive influence on the effective selection of staff.

$\mathrm{H}_{2}$ : The knowledge test has a positive influence on the effective selection of personnel.

$\mathrm{H}_{3}$ : The personality test has a positive influence on the effective selection of personnel. 


\section{Method}

A deductive study, of an explanatory level with a non-experimental design, was carried out between December 2019 and December 2020.

\subsection{Population and sample}

For the present research, the study population was made up of employees of companies in the retail sector, among men and women in the age range of 22 to 37 years and older, who are responsible for the process of recruiting and selecting personnel, belonging to the area of human resources, in the department of Junín had an increase of 4.7\% between 2017 and 2018 from 86327 companies to 90424 (National Institute of Statistics and Information [INEI], Corporate Structure 2018) with a margin of error of $5 \%$.

\subsection{Data collection instrument}

For the collection of information, a questionnaire was developed consisting of 15 questions that determine the effectiveness of personnel selection ( 5 from interviews, 5 from knowledge tests and 5 from personality tests). For the validation of the instrument, the Delphi methodology was considered. Three experts in Administration, Human Resources and Organizational Psychology validated the form by applying the survey to 120 collaborators belonging to the human resources area, who participated simultaneously. After the expert's first observation, the pertinent observations were raised by modifying certain questions, refining the data collection mechanism, and the instrument was moved to a second application with a sample of 106 collaborators belonging to the human resources area. For the form and substance validation, the 4 point Likert scale was considered for the evolution of the questions (the first one totally disagreed and the fourth one totally agreed), so at the end of this process it reached an average score that was higher than .605 , each dimension obtained a higher score according to Cronbach's alpha parameters.

\section{Method}

\subsection{Evaluation of the measurement model}

Table 1 shows the measurement analysis of the model, based on the reliability and validity of the measurement scales. With respect to reliability, the internal consistency of the scales is evidenced by the Cronbach Alpha value (between 0.506 and 0.858 ) and the composite reliability (between 0.786 and 0.896 ). With respect to convergent validity, all factor loads are above 0.800. Likewise, all scales have average extracted variance (AVE) percentages greater than $50 \%$. The discriminant validity of the construct was tested by the criteria of Fornell Larcker, who verified the independence of each of the scales, considering that the square root of the AVE is greater than the correlations with the rest of the scales. In all cases, the assumption was fulfilled.

Table 1

Results of the model measurement analysis

\begin{tabular}{|c|c|c|c|c|c|}
\hline Variables & $\begin{array}{c}\text { Cronbach's } \\
\text { Alpha }\end{array}$ & $\begin{array}{l}\text { Composite } \\
\text { Reliability }\end{array}$ & $\begin{array}{c}\text { Factorial loads } \\
\text { (range) }\end{array}$ & $\begin{array}{l}\text { Average Variance } \\
\text { Extracted (AVE) }\end{array}$ & $\begin{array}{c}\text { Discriminant } \\
\text { validity }\end{array}$ \\
\hline Interview & 0.801 & 0.878 & $0.689-0.915$ & 0.708 & 0.842 \\
\hline Knowledge test & 0.751 & 0.855 & $0.735-0.880$ & 0.664 & 0.815 \\
\hline Personality test & 0.858 & 0.896 & $0.662-0.903$ & 0.685 & 0.828 \\
\hline ESP & 0.506 & 0.786 & $0.669-0.926$ & 0.653 & 0.808 \\
\hline
\end{tabular}

As shown in Fig. 2, in all cases a R2 DE 0.555 greater than 0.100 was obtained, which is very significant, showing that the model significantly explains the variance of the conceptual constructs of the dependent variable.

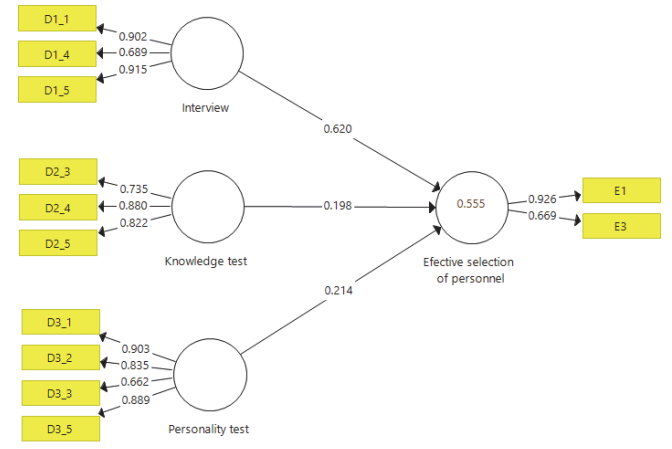

Fig. 2. Results of the hypothetical model with structural equations

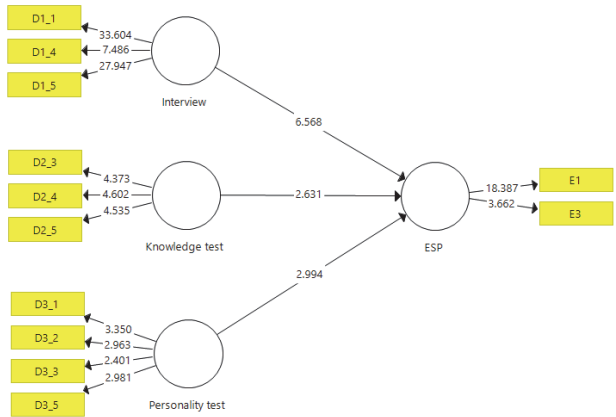

Fig. 3. Digital transformation modeling and individual work performance 


\subsection{Evaluation of the structural model}

After verifying the validity and reliability of the measurement model, the relationships of the constructions were tested. The hypotheses were tested by examining the road coefficients and their levels of significance. Bootstrapping was performed with 5000 subsamples to verify the statistical significance of each of the road coefficients (Vicente-Ramos et al., 2020). Fig. 3 shows the estimated path of PLS analysis. Considering that the 3 specific relations have $\mathrm{p}<0.05$, all the proposed hypotheses are accepted as shown in Table 2.

Table 2

Results of the model structure analysis

\begin{tabular}{cccccc}
\hline Hypothesis & Average sample & Standard deviation & Beta & Value p & Decision \\
\hline Interview $\rightarrow$ ENG & 0.622 & 0.094 & 6.568 & 0.000 & Accepts H1 \\
Knowledge test $\rightarrow$ ENG & 0.189 & 0.075 & 2.631 & 0.009 & Accepts H2 \\
Personality test $\rightarrow$ ESP & 0.229 & 0.072 & 2.994 & 0.003 & Accepts H3 \\
\hline
\end{tabular}

\section{Discussion and conclusion}

\subsection{With respect to the interviews in the selection of personnel}

As a result, a high influence was obtained between the interview and the selection of personnel, obtaining (0.801) according to Cronbach's alpha and one obtained a significance of $\mathrm{p}=0.000$ less than 0.05 therefore the $\mathrm{H} 1$ is accepted, a high correlation between the two variables is reaffirmed, (Robles, 2011) which mentions that the main purpose of the in-depth interviews is to go deeper and detail the life of the interviewee to decipher and understand their achievements, likes, fears, satisfactions, anguishes, frustrations and joys, Diaz, Torruco, Martinez and Valera (2013) mention the effectiveness of the interview compared to the questionnaires, since this tool provides more complete and in-depth information and allows the possibility of clarifying doubts during the process, thus ensuring more useful responses. The advantage generated by the use of the interview, is the possibility of focusing the topic towards a specific objective or focus on a specific topic, giving possibilities to find out own information (opinions, suggestions, attitudes, motives and behavioral motivations), thus ensuring the effectiveness of the process of recruitment and selection of personnel for the required position guaranteeing the productivity of the worker.

\subsection{With regard to the tests of knowledge in the selection of personnel}

It has been obtained as a result a high influence between the tests of knowledge and the selection of the personnel obtaining an alpha of Cronbach of (0.751) and one was obtained a significance of $\mathrm{p}=0.009$ smaller to 0.05 therefore the H1 is accepted, a high correlation between the two variables is reaffirmed, likewise Martinez and Vargas (2019) determine that the selection of personnel offers the possibility of orienting and classifying the people according to its potentialities, capacities and to contribute to the formation and development of the candidates. On the other hand Peñaloza and Arevalo (2007) affirmed that, from a managerial approach, the psychological, technical, administrative and operational competencies provide key elements such as work performance, stress management, perception of attitudes, ethics, confidence, thus estimating the potential of the personnel, considering also the benefits of a system based on competencies, as a system that constitutes a tool to define knowledge, the intellectual coefficient and abilities of the collaborators, required to reach the objectives of the company, in this way the labor efficiency of the worker is guaranteed by means of the adequate and effective use of intellectual coefficient tests in the selection of personnel.

\subsection{Regarding personality tests in the selection of personnel}

It has been obtained as a result a high influence between the tests of knowledge and the selection of the personnel obtaining an alpha of Cronbach of (0.858) and one was obtained a significance of $\mathrm{p}=0.003$ smaller to 0.05 therefore H1 is accepted, a high correlation between the two variables is reaffirmed, likewise Alonso, Moscoso and Cuadrado (2015) in their investigation indicated that many companies have included the evaluation of characteristics of personality in processes of selection, mainly in those made in individual practices. The psychometric reviews carried out have shown that personality factors can predict several organizational criteria such as: job performance, success in training, staff turnover, job satisfaction, counterproductive behaviors or career line potential. In addition, Merlyn-Sacoto et al. (2018) mention that both internal and external traits of a person, determine the success that this person may have in achieving their functions, since personality traits and factors act as independent variables or predictors of job performance. Finally, the field of personnel recruitment is a broad branch that varies over the years and the integration of new generations in the labor field, other selection techniques can be implemented in conjunction with existing ones such as participant observation and self-observation, life stories and / or oral history, photo biographies, discussion groups, recreated scenes, which would be helpful to cover spaces within the selection of personnel.

\section{References}

Alonso, P., Moscoso, S., \& Cuadrado, D. (2015). Personnel selection procedures in Spanish small and medium size organizations (Manuscript in Spanish). Revista de Psicología del Trabajo y de las Organizaciones, 31(2), 79. 
Amador, J. (2013). Wechsler Intelligence Scale for Adults-IV (WAIS-IV). Dipósit Digital of the University of Barcelona.

Calderón, G., Acosta, D., \& Gallego, J. (2017). Trends in personnel selection methods in companies in the city of Medellín. CIES, 8(2), 131-141.

Castaño, M., López, G., \& Prieto, J. (2011). Technical guide and good practices in recruitment and selection of personnel. Madrid: Official College of Psychologists of Madrid.

Chiavenato, I. (2007). Human Resource Management (Eighth ed.). Mexico: McGrawHill.

Chiavenato, I. (2011). Human Resource Management (Ninth ed.). Mexico: Mc Graw Hill.

Díaz, L., Torruco, U., Martínez, M., \& Varela, M. (2013). The interview, a flexible and dynamic resource. Research Methodology in Secondary Education, 2(7), 162-167.

Ferro, R., \& Vives, C. (2004). An analysis of the concepts of effectiveness, efficacy and efficiency in psychology. ResearchGate.

Fong, J. (2019). Psychometric tests, what are they and how are they classified?

González, F. (2007). Psychological evaluation instruments. Havana: Medical Sciences.

INEI. (November 2019). Peru business structure. Retrieved from https://www.inei.gob.pe/media/MenuRecursivo/publicaciones digitales/Est/Lib1703/libro.pdf

Jiménez, F., \& Iguiñiz, J. (2010). The Peruvian economy of the last half century: interpretation essays. Lima: CISEPA-PUCP.

Kanning, U. P., \& Kuhne, S. (2006). Social desirability in a multimodal personnel selection test battery. European Journal of Work and Organizational Psychology, 15(3), 241-261.

Martínez, O., \& Vargas, T. (2019). Procedimiento para la gestión del proceso de reclutamiento y selección del personal en función del desarrollo local. Cooperativismo y Desarrollo: COODES, 7(2), 225-242.

Matabajoy-Montilla, J. M., Matabachoy-Tulcán, S. M., \& Obando-Guerrero, L. M. (2018). Human talent development processes in a specialty clinic in Pasto, Colombia. Universidad y Salud, 20(1), 26-36.

Merlyn-Sacoto, M. F., Acurio-Velasco, C. V., Cabezas-Guerra, C. B., Orbe-Nájera, C. E., \& Riera-Vásquez, W. L. (2018). Rasgos de personalidad que afectan el desempeño de los profesores de la PUCE matriz en las funciones de docencia e investigación. Estudios pedagógicos (Valdivia), 44(1), 331-349.

Pascale, D., Asselin, S., \& Paré, F. (2013). Sélectionner les candidats au moyen de tests psychométriques: Qu'enseignent la doctrine et la jurisprudence québécoises?. Canadian Psychology/Psychologie canadienne, 54(4), 269.

Peñaloza, M., \& Arévalo, F. (2007). Evaluación por competencias y estimación de potencial en las empresas eléctricas de occidente. Revista de Ciencias Sociales (Ve), 13(1), 116-133.

Robles, B. (2011). La entrevista en profundidad: una técnica útil dentro del campo antropofísico. Cuicuilco, 18(52), 39-49.

Tovar, J. (2007). Psicometría: tests psicométricos, confiabilidad y validez. Psicología: Tópicos de actualidad, 85-108.

Vargas, L. F. (2016). Construcción de pruebas psicométricas: aplicaciones a las ciencias sociales y de la salud Livia, J. \& Ortiz, M.(2014) Lima: Editorial Universitaria. 166 p. Revista Digital de Investigación en Docencia Universitaria, 10(2), 92-94.

Vicente-Ramos, WE, Silva, BG, Merino, STN, Lazo, SMP, \& Álvarez, CRM (2020). Academic Motivations of Pregrade Students in the Choice of International Business Career. International Journal of Higher Education, 9(2), 85-94.

Wayne, M. (2010). Human Resources Administration - Eleventh Edition. Mexico: Pearson Education.

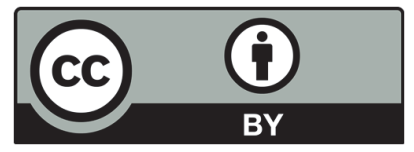

(C) 2021 by the authors; licensee Growing Science, Canada. This is an open access article distributed under the terms and conditions of the Creative Commons Attribution (CC-BY) license (http://creativecommons.org/licenses/by/4.0/). 